\title{
ИНТЕРНАЦИОНАЛИЗАЦИЯ ОБРАЗОВАНИЯ
}

DOI: https://doi.org/10.31992/0869-3617-2020-29-1-156-165

\section{Тьюторское сопровождение как инструмент социокультурной адаптации иностранных студентов в российском вузе}

Береговая Оксана Александровна - канд. филос. наук, доцент. E-mail: zaroza@mail.ru

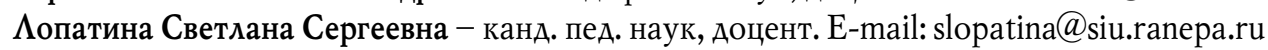
Отургашева Наталья Вадимовна - канд. филол. наук, доцент. E-mail: vialuna@list.ru Сибирский институт управления - филиал Российской академии народного хозяйства и государственной службы при Президенте РФ

Адрес: 630102, г. Новосибирск, ул. Нижегородская, 6

Аннотащия. В условиях усиливающейся интерначионализачии высшего образования привлечение студентов из-за рубежа рассматривается как одно из средств усиления позииии страны в мировом образовательном пространстве. Выполнение вузами данного показателя осложнено необходимостью системно, комплексно изменять образовательный и воспитательный прочесс и создавать благоприятные условия для студентов из числа иностранньх граждан. Цель данной статьи - рассмотреть тьюторское сопровождение как инструмент сочиокультурной адаптачии иностранных студентов и возможности его применения $b$ российских вузах. Авторами были проанализировань понятия «сочиокультурная адаптачия", "тьюторское сопровождение», показана их взаимосвязь.

В статье рассмотрены такие приниипь современного образования, как открытость, вариативность, диалогичность, индивидуализачия, создание избыточной информачионной средь, и показано соответствие этим приниипам практики тьюторского сопровождения. Представлена также програмла обучения тьюторов из студенческой средь и раскрыто содержание и формь реализачии образовательньх модулей данной программьь.

По итогам анализа опьта работы школь тьюторов и волонтёров в Сибирском институте управления - филиале РАНХиГС авторами сделан выьод о перспективах и возможностях использования студенческого тьюторства в качестве инструмента адаптачии иностранных учашихся к обучению в российских вузах и эффективного способа их вовлечения $b$ совместную социокультурную деятельность, позволяюшую раскрыть и развить имеющийся личностный и образовательный потенииал студентов-иностраниев. Предложен опьыт подготовки студентов-тьюторов, деятельность которых направлена на создание благоприятных условий сочиокультурной адаптачии иностранных студентов в российском вузе на примере Сибирского института управления - филиала РАНХиГС.

Ключевые слова:иностранные студенть, интерначионализачия, тьютор, тьюторское сопровождение, подготовка студентов-тьюторов, сочиокультурная адаптачия, индивидуализачия, благоприятная среда вуза

Аля иитирования: Береговая О.А., Аопатина С.С., Отургашева Н.В. Тьюторское сопровождение как инструмент социокультурной адаптации иностранных студентов в российском вузе // Высшее образование в России. 2020. Т. 29. № 1. С. 156-165.

DOI: https://doi.org/10.31992/0869-3617-2020-29-1-156-165 


\section{Введение}

С конца 1980-х гг. обозначились ключевые трансформации в сфере высшего образования развитых стран: рост его массовости, расширение доступа и интернационализация. Они связаны с активизацией международной студенческой мобильности. По данным опубликованного в 2018 г. очередного обзора систем образования разных стран, в США обучается 971 тыс. иностранных студентов, в Великобритании - 432 тыс., в Австралии - 336 тыс., в России - 250 тыс. чел. ${ }^{1}$ За последние десятилетия возросла конкуренция вузов за привлечение иностранных студентов благодаря созданию для них благоприятной среды для обучения и проживания в принимающей стране.

\section{Постановка проблемы, цели исследования}

В российских вузах образовательная среда ещё не в полной мере адаптирована Аля обучения иностранцев. По мере роста глобальной политической напряжённости, вызывающей опасения у иностранных студентов в отношении толерантного к ним отношения со стороны местного населения, в вузах востребованы специальные мероприятия, направленные на создание комфортной среды пребывания. Проведённое ранее исследование авторов статьи по выявлению барьеров социокультурной адаптации иностранных студентов в российских вузах [1] показало, что быстрое или медленное протекание данного процесса отражается на качестве жизни и академических успехах иностранных учащихся, а также зависит от того, как и с помощью чего преодолеваются трудности.

Тьюторское сопровождение в условиях российской высшей школы ещё не приобрело системного характера, но накопленный опыт уже обобщается [2; 3]. Несмотря

${ }^{1}$ Education at a glance 2018: OECD indicators. Paris: OECD Publishing. URL: https://www.oecd-ilibrary.org/docserver/eag-2018-en.pdf?expires $=157$ $4584015 \& \mathrm{id}=\mathrm{id} \&$ accname $=$ guest $\&$ checksum $=84 \mathrm{C}$ FE7A1A3F3DFF75B30440010439CF7. P. 228. на то, что позиция тьютора появилась в профессиональном стандарте как педагогическая профессия, в большинстве вузов внедрение института тьюторства до сих пор расценивается как инновация. Кроме того, само понимание тьюторских практик и технологий крайне противоречиво. Причина в том, что в понятие «тьютор» вкладываются многие смыслы: наставник, ментор, фасилитатор, коуч и т.д.

Цели данного исследования: определить понятие «тьютор»; выявить роль тьюторства как инструмента социокультурной адаптации иностранных студентов; показать возможности студенческого тьюторства; представить опыт школы тьюторов и волонтёров Аля работы с иностранными студентами в Сибирском институте управления - филиале РАНХиГС при Президенте РФ.

\section{Обзор литературы}

В отечественной и зарубежной литературе предлагаются различные подходы к преодолению адаптационных барьеров студентами-иностранцами. Чаще всего типологизация инструментов адаптации идёт вслед за классификацией трудностей (барьеров) социокультурной адаптации. И.О. Кривцова отмечает, что иностранные студенты преодолевают «разного рода психологические, социальные, нравственные, религиозные барьеры», осваивают «новые виды деятельности и формы поведения» [4, c. 284]. Социокультурная адаптация - это процесс и результат внутреннего самоизменения иностранных студентов, их внешнего приспособления к новой среде (языку, культуре, менталитету, социальным нормам, особенностям быта, к жизни в университете). Трудности социокультурной адаптации усугубляются тем, что иностранные студенты-первокурсники переживают те же проблемы, что и российские студенты-первокурсники: переход из школы в вуз, переход в новую социальную группу, адаптация к новым методам и формам обучения, вхождение в новый коллектив и т.п. 
В современной отечественной и зарубежной литературе инструменты адаптации описаны с разных позиций: психологопедагогической [5], социокультурной [6], коммуникативной [7], организационной [8], технологической [9]. Практика в российских вузах показывает, что суть помощи в адаптации понимается по-разному. Широко применяется создание служб психолого-педагогического сопровождения иностранных студентов [4-6, 10; 11]; служб кураторов, наставников, воспитателей; центров поддержки иностранных студентов [4-6, 12]. В одних вузах организованы студенческие клубы, где российские и иностранные студенты знакомятся с особенностями культуры разных народов, а студенты-волонтёры помогают иностранцам решать их бытовые проблемы, в других работа по адаптации сводится к изучению русского языка и проведению национальных праздников [13].

Общим понятием, объединяющим характеристики инструментов адаптации, может быть «сопровождение». Оно означает буквально «вместе с кем-нибудь, сопровождаемый кем-нибудь», «то, что сопровождает что-нибудь, какое-то явление или процесс» ${ }^{2}$. Важную роль здесь играет приставка «со-», подчёркивающая взаимодействие или совместные действия людей друг с другом. Аля наглядности эту приставку можно написать через дефис: со-участие, со-творчество сопровождаемого и того, кто сопровождает.

Феномен тьюторства известен практически 900 лет. Его корни уходят в средневековую историю европейских университетов, прежде всего английских - Оксфордского и Кембриджского. Тогда оно представляло собой форму университетского наставничества [14, с. 71-72]. В традиционную структуру тьюторской деятельности входило: «руководство занятиями (кураторство), обеспечивающее учёбу студентов и работу

\footnotetext{
${ }^{2}$ Ожегов С.И. Словарь русского языка / Под ред. Н.Ю. Шведовой. М.: Русский язык, 1986. C. 630 .
}

в каникулярное время; моральное наставничество, предполагающее сопровождение жизни студента в университете в самом широком смысле слова; собственно тьюторство, осуществляющее обучение студента в течение триместра или учебного года» $[15$, с. 76]. Тьюторство широко распространено в современных зарубежных вузах Великобритании, США, Германии, Франции и др. В этих странах сложились свои традиции его осуществления на практике и их теоретическое обоснование [16].

Интерес к тьюторству в России не только обрёл практический характер, но и не так давно оказался в центре внимания научного сообщества [3]. В трудах Т.М. Ковалевой [17], И.А. Проскуровской [15] и Ар. изучены не только исторические истоки тьюторства за рубежом и в России, но и прикладные аспекты, возможности применения тьюторской модели в условиях отечественного образования. Тьюторство в научной литературе определяется и как психолого-педагогическая деятельность, и как культурная позиция, и как социальная работа. При этом выделяют три типа тьюторских практик, представленных, соответственно, тремя контекстами: информационным, социальным и антропологическим [9, с. 63]. Тьюторское сопровождение удовлетворяет потребности перехода к индивидуализации процесса обучения и вариативности образовательных программ, способствует профессиональноличностному развитию студентов и выступает средством активизации их самостоятельной работы и самоорганизации. Таким образом, тьюторское сопровождение в высшем образовании призвано решать целый комплекс проблем. Мы понимаем тьюторство как особый тип сопровождения образовательной деятельности человека в ситуациях неопределённого выбора, когда обучающийся выполняет образовательные действия, а тьютор создаёт условия для их осуществления и осмысления.

В научной литературе подробно представлен разнообразный репертуар тьютор- 
ских позиций в современной академической среде: тьютор-стажёр (студент старших курсов) помогает новичкам осваивать университетское пространство, академический тьютор (магистр со специальной подготовкой) отвечает за разработку и реализацию учебного плана, тьютор-наставник (выпускник вуза, профессионах) поддерживает процесс формирования необходимых для будущего специалиста навыков, умений, компетенций и, наконец, тьютор-супервизор (профессор) организует и курирует процесс тьюторской рефлексии [5; 18]. Такая разветвлённая система тьюторского сопровождения обеспечивает важнейшие принципы современного образования - его гибкость и непрерывность, а также учитывает индивидуальные особенности, трудности и проблемы обучения иностранных студентов в российских вузах. Тьюторское сопровождение можно рассматривать как эффективный механизм социокультурной, языковой и образовательной адаптации учебных мигрантов [12].

\section{Опыт вуза}

Среди множества моделей тьюторского сопровождения следует обратить особое внимание на примеры студенческого тьюторства в рамках программ академического обмена. Из них отметим: The Critical Language Scholarship (CLS) (CША) по интенсивному изучению иностранного языка; систему тьюторинга РУАН, которая объединяет тьюторов-воспитателей и кураторов иностранных студентов на подготовительном факультете, тьюторов-воспитателей и тьюторов по учебной работе, а также кураторов учебных групп на основных факультетах, тьюторов-воспитателей отдела по работе в студенческих общежитиях, тьюторов-организаторов воспитательной работы среди иностранных студентов в земляческих организациях; студенческие тьюторские и волонтёрские сообщества по работе с иностранными студентами в Томском государственном университете, Тюменском государственном университете, Новосибирском национальном исследовательском университете, Университете Ювяскюля (Финляндия) и др. Аалее будет представлен опыт организации Школы тьюторов и волонтёров для работы с иностранными студентами в Сибирском институте управления - филиале РАНХиГС (далее - Школа). Участниками Школы в 2019 г. стали семь российских студентов и пять иностранных: из Кыргызстана, Узбекистана, Монголии.

Цель практических занятий в Школе для студентов состоит в том, чтобы не только получить теоретические знания и практические навыки по тьюторскому сопровождению, но и реализовать потребности в самообразовании, самовоспитании и личностном самосовершенствовании. На таких занятиях участники Школы получают знания начальных основ межкультурной коммуникации, психологии, осознают социокультурные барьеры, которые возникают у иностранных учащихся в России. В организации занятий в Школе реализуется принцип совместной деятельности, сотворчества, индивидуализации. Содержание занятий построено по модульному принципу и состоит из четырёх модулей, охватывающих как теоретические, так и практические проблемы.

Первый модуль - «Основы индивидуализации и тьюторского сопровождения иностранных обучающихся»- вкдючает в себя семинар-тьюториал «Философия и методология тьюторства», практические занятия по темам «Особенности тьюторского сопровождения иностранных студентов», «Составляющие тьюторской деятельности». Цель данного модуля - знакомство с основными принципами тьюторского сопровождения и освоение соответствующих навыков на практике.

Построение диалога тьютора со студентом может быть успешным лишь при условии понимания и принятия Аругого, его системы ценностей и смыслов, т.е. при наличии субъект-субъектных отношений между учеником и его наставником. В современных условиях, когда принцип свободного развития индиви- 
дуальности, реализуемый через социальную деятельность и самовыражение, является целью и ценностью общества, выбор индивидуальной траектории движения к получению образования является важнейшей стратегией тьюторских практик. Этот выбор должен быть обусловлен запросами, интересами, возможностями, мотивацией обучающегося, его осознанным желанием получить качественное образование. В свою очередь, сама возможность выбора предполагает создание в вузе избыточной информационной среды, необходимой обучающемуся для расширения академических, интеллектуально-познавательных и организационных ресурсов. Создание подобной среды позволит дичности, при наличии подготовленного тьюторапомощника, осуществить адекватный выбор траектории саморазвития и в полной мере реализовать имеющийся образовательный потенциал.

Второй модуль называется «Основы межкультурной коммуникации». Занятия построены в форме тренингов. Совместное обучение российских и иностранных студентов открывает возможности для межкультурного общения и диалога культур. Цель изучения модуля - развить навыки межкультурной коммуникации через знакомство с разными практиками общения. Аюбая программа поддержки иностранных студентов должна строиться на принятии и уважении культурных, национальных, расовых и этнических различий. Иностранные студенты испытывают трудности не просто в общении на русском языке, а в общении с людьми другой культуры, что предполагает знание правил речевого этикета. Занятия в данном модуле нацелены на знакомство с культурой России и русским менталитетом. Занятия по межкультурной коммуникации обучают студентов-тьюторов способам взаимодействия с представителями различных этнических общностей на основе понимания культурных различий и диверсификации в обществе; способствуют формированию необходимых навыков межкультурной коммуникации и решения конфликтных ситуаций. Опираясь на опыт организации тьюторского сопровождения в РУАН, можно сделать вывод, что основная задача ведущих преподавателей - объяснить студентам «объективные причины подобных различий, обратить их внимание на объединяющие мотивы их присутствия в вузе, общие черты жизни и характера любого человека и призвать их к пониманию и толерантности» [6, с. 31].

Третий модуль - «Основы психологопедагогических знаний» - включает практические занятия по темам «Технологии педагогического общения», «Практика индивидуализации обучения русскому языку как иностранному». Цель изучения модуля - сформировать у слушателей Школы представление о психолого-педагогических явлениях образовательного процесса, закономерностях и механизмах, сопровождающих обучение и воспитание, развить способность проектирования и проведения образовательной и воспитательной работы с иностранными студентами. Цель тьютора, работающего с иностранными студентами, - стать помощником и советчиком. В процессе работы с иностранными студентами тьютор не только помогает им выстраивать индивидуальную траекторию личностного развития, но и оказывает помощь в освоении дисциплин, в том числе русского языка.

Аля достижения поставленной цели в процессе подготовки студентов необходимо решить следующие задачи: освоить основные технологии педагогического общения; обеспечить практическое владение технологиями разработки и реализации индивидуальных стратегий психолого-педагогического сопровождения иностранных студентов; обеспечить практическое владение приёмами проектирования деятельности, диагностической работы, необходимой для деятельности тьютора. В рамках темы «Технологии педагогического общения» проходит знакомство с приёмами и способами умственной деятельности, особенностями формирования мыслительных процессов, методами управ- 
ления процессами учения, основами мотивационного обеспечения учебного процесса и др. Студент-тьютор должен владеть множеством компетенций, важнейшей из которых является педагогическая компетентность: способность к эмпатии, конструктивному диалогу, толерантность, владение современными интерактивными технологиями обучения, связанными с умением передавать знания по предмету, умением управлять образовательным процессом.

При изучении темы «Практика индивидуализации обучения РКИ» необходимо подчеркнуть, что студенты-тьюторы не являются филологами, поэтому не могут оказывать профессиональную помощь в углублении знаний по русскому языку, однако в их силах помогать иностранным студентам пополнять лексический запас, правильно строить предложения, читать и анализировать тексты. Студенты самостоятельно готовят и проводят дополнительные семинарские занятия по русскому языку с иностранными студентами, развивая на каждом занятии все виды речевой деятельности. При помощи интерактивных методов обучения студенты моделируют ситуации общения, готовят интерактивные экскурсии, обучающие проекты для иностранных студентов.

Иностранные студенты под руководством студентов-тьюторов могут сделать простые письменные упражнения, например, выписать из текста все глаголы, поставив их в форму прошедшего или будущего времени, выписать из текста имена существительные, определить род, число, падеж и др. При отработке навыков аудирования (слушания) студенты-тьюторы могут записывать аудиотексты самостоятельно (это могут быть небольшие фрагменты текста, которые иностранные студенты смогут воспроизвести) или предлагать другие задания, например, составить вопросы к тексту, написать своё мнение об услышанном и др. Таким образом, студенты-тьюторы, безусловно, не могут заменить филолога, но на своих «шефских занятиях» помогают иностранцам дополни- тельно отрабатывать разные виды речевой деятельности.

Четвёртый модуль - «Волонтёрская деятельность в студенческой среде и организация мероприятий для иностранных студентов» ориентирован на подготовку внеаудиторных мероприятий силами самих студентов. Цель модуля - сформировать у будущих тьюторов навыки разработки и реализации социокультурных проектов в студенческой среде для иностранных учащихся. Содержание занятий посвящено проектной деятельности через освоение следующих этапов: разработка идеи, анализ ситуации, постановка целей и задач, осмысление этапов реализации, анализ ресурсов и аудитории, выбор механизмов реализации, прогнозирование результатов. При этом разработчики проектов должны учитывать потребности иностранных студентов, обучающихся в конкретном вузе.

Занятия проводятся в интерактивной форме, в формате малых групп, включающих как российских, так и иностранных учащихся. Такой состав групп позволяет иностранцам успешнее усваивать теоретический материал, а впоследствии эффективнее выбирать темы будущих мероприятий, определять их цели, разрабатывать стратегии реализации. Подобные занятия сами по себе становятся действенным инструментом социальной и психологической адаптации иностранных студентов. Они находят себе друзей, обсуждают возникшие проблемы, знакомятся с преподавателями вне традиционных рамок учебного процесса, осваивают новую Аля себя деятельность по подготовке мероприятий и проектов. Участие в социокультурных проектах имеет для иностранных студентов особое значение: по свидетельству специалистов, словарный запас русского языка увеличивается у них на 30-40 слов после каждого такого мероприятия [13].

\section{Заключение}

На разных этапах обучения в вузе иностранные студенты сталкиваются с различными проблемами. Если в начале обучения 
это прежде всего трудности бытового, языкового и социокультурного характера, то на завершающем курсе - профессиональнокомпетентностные и организационные. Разная «специализация» тьюторов позволяет своевременно и адекватно реагировать на возникающие трудности и не только курировать образовательный процесс на всём его протяжении, но и помогать выпускнику вуза после его окончания.

Организация студенческого тьюторства - это отличное дополнение к другим инструментам социокультурной адаптации иностранных студентов. Решение неотложных вопросов бытового, учебного, организационного характера может быть возложено на студентов старших курсов, специально подготовленных для подобной работы. Их вовлечение в совместную с преподавателями деятельность по социокультурной адаптации иностранных студентов создаёт необходимые условия для полноценной реализации культурно-образовательного потенциала всех участников тьюторского движения, помогает реализовать ресурсные возможности личности, вовлечённой в образовательновоспитательный процесс вуза.

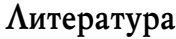

1. Береговая О.А., Аопатина С.С., Отургашева $H . B$. Барьеры социокультурной адаптации иностранных студентов в российских вузах // Перспективы науки и образования. 2019. № 2 (38). C. 108-118.

2. Аорожкин Ю.Н., Мазитова А.Т. Проблемы социальной адаптации иностранных студентов // Социологические исследования. 2007. № 3. C. 73-77.

3. Становление тьюторской модели современного университета в России / Науч. ред. Т.М. Ковалева, А.О. Зоткин, Е.А. Суханова. Томск: ИзА. дом Томского гос. ун-та, 2019. 256 с.

4. Кривцова И.О. Социокультурная адаптация иностранных студентов к образовательной среде российского вуза (на примере Воронежской государственной медицинской академии им. Н.Н. Бурденко) // Фундаментальные исследования. 2011. № 8 (часть 2). C. 284-288.
5. Беляева Т.К., Никишина О.А. Тьюторство как ресурс повышения качества образования иностранных студентов в вузе // Современные проблемы науки и образования. 2015. № 6. URL: http://science-education.ru/ru/ article/view? $\mathrm{id}=22754$

6. Гладуш А.А., Трофимова Г.Н., Филиппов B.M. Социально-культурная адаптация иностранных граждан к условиям обучения и проживания в России. М.: РУАН, 2008. 146 с.

7. Самохвалова А.Г., Амитрук А.А. Коммуникативные трудности межкультурного общения китайских и российских студентов // Ярославский педагогический вестник. 2019. № 4(109). C. 86-94. DOI: https://doi. org/10.24411/1813-145X-2019-10456

8. Гребенникова И.А. Адаптация иностранных студентов: механизмы и факторы // Гуманитарные исследования в Восточной Сибири и на Аальнем Востоке. 2011. № 3. С. 98-100.

9. Ковалева Т.М. Реализация принципа открытости при построении и применении образовательных технологий // Отечественная и зарубежная педагогика. 2014. № 4. С. 63-71.

10. Иванова Г.П., Иогвинова О.К., Ширкова Н.Н. Педагогическое обеспечение социокультурной адаптации иностранных студентов: опыт реализации // Высшее образование в России. 2018. T. 27. № 3. C. 60-69.

11. Gladkova A.A. Psychological and socio-cultural adaptation of international journalism students in Russia: The role of communication skills in the adaptation process// Psychology in Russia: State of the Art. 2017. Vol. 10. Issue 4. P. 45-59. DOI: http://dx.doi.org/10.11621/pir.2017.0405

12. Казанщева А.А. Тьюторское сопровождение процесса адаптации иностранных студентов в вузе // Высшее образование в России. 2012. № 10. C. 157-161.

13. Кирилова Ю.С. Культурно-массовая деятельность как один из важных способов адаптации иностранных студентов в Томском политехническом университете // Международный журнал прикладных и фундаментальных исследований. 2015. № 5-4. С. 670-672.

14. Беличкая Е.В. Современное состояние тьюторской системы обучения в университетах Англии // Alma mater (Вестник высшей школы). 2012. № 4. С. 71-75.

15. Проскуровская И.А. Опыт реконструкции исторических оснований тьюторства (на материале истории английских университетов) 
// Вестник Томского государственного университета. Философия. Социология. Политология. 2009. № 2(6). С. 71-81.

16. Гордон Э., Морган Р., О’ Мэлли Ч., Понтиселл Аж. Революция в тьюторстве: прикладное исследование передового опыта, вопросов политики и достижений учащихся / Пер. с англ., под науч. ред. С.Ф. Сироткина, M.А. Мельниковой. Ижевск: ERGO, 2010. $332 \mathrm{c}$.

17. Ковалева Т.М., Чередилина М.Ю. Тьюторство как ресурс для системы развивающего обучения А.Б. Эльконина - В.В. Аавыдова. М.: Авторский клуб, 2015.56 с.

18. Волченкова К.Н. Тьюторское сопровождение как основа субъект-субъектных отношений тьютора и студента // Вестник Южно-Уральского государственного университета. Образование. Педагогические науки. 2013. Т. 5. № 3. C. 71-76.

Статья поступила в редакиию 12.10 .19

После доработки 19.11.19

Принята к публикачии 30.11 .19

\section{Tutor Support as a Tool of Social-Cultural Adaptation of International Students in Russian Universities}

Oksana A.Beregovaya - Cand. Sci. (Philosophy), Assoc. Prof., e-mail: zaroza@mail.ru Svetlana S.Lopatina - Cand. Sci. (Education), Assoc. Prof., e-mail: slopatina@siu.ranepa.ru NataliaV.Oturgasheva - Cand. Sci. (Philology), Assoc. Prof., e-mail: vialuna@list.ru Siberian Institute of Management, Branch of RANEPA, Novosibirsk, Russia Address: 6, Nizhegorodskaya str., Novosibirsk, 630102, Russian Federation

Abstract. In the conditions of increasing internationalization of higher education, attracting students from abroad is considered as one of the means of strengthening the country's position in the world educational space. At the same time, the implementation of this indicator is complicated by the need to systematically, comprehensively change the educational and educational process and create favorable conditions for students from among foreign citizens. The purpose of this article is to consider tutor support as a tool of sociocultural adaptation of international students and its application in Russian universities. The authors analyze the concepts of "socio-cultural adaptation", "tutor support" and show their relationship.

The article considers such principles of modern education as openness, variability, dialog, individualization, creation of open information environment, and shows compliance with these principles of tutor support practice. The program of training of student tutors is presented and the content and forms of implementation of educational modules of this program are revealed.

As a result of the analysis of the experience of the School of tutors and volunteers in Siberian Institute of management, the branch of RANEPA it is concluded about the prospects and opportunities of using student tutoring as a tool for adapting international students to study in Russian universities and an effective way of their involvement in joint sociocultural activities, allowing to reveal and develop their existing personal and educational potential. The experience of training students-tutors is aimed at creating favorable conditions for socio-cultural adaptation of international students in Russia.

Keywords: international students, internationalization, tutor, tutor support, student tutoring, socio-cultural adaptation, individualization, supportive environment

Cite as: Beregovaya, O.A., Lopatina, S.S., Oturgasheva, N.V. (2019). Tutor Support as a Tool of Social-Cultural Adaptation of International Students in Russian Universities. Vysshee obrazovaniev Rossii = Higher Education in Russia. Vol. 29, no. 1, pp. 156-165. (In Russ., abstract in Eng.)

DOI: https://doi.org/10.31992/0869-3617-2019-29-1-156-165 


\section{References}

1. Beregovaya, O.A., Lopatina, S.S., Oturgasheva, N.V. (2019). Barriers to Socio-Cultural Adaptation of Foreign Students in Russian Universities. Perspektivy nauki $i$ obrazovania $=$ Perspectives of Science and Education. Vol. 2, no. 38, pp. 108-118. DOI: https://doi.org/10.32744/ pse.2019.2.9 (In Russ., abstract in Eng.)

2. Dorozhkin, Yu.N., Mazitova, L.T. (2007). Problems of Social Adaptation of Foreign Students. Sotsiologicheskie issledovaniya $=$ Sociological Studies. No. 3, pp. 73-77. (In Russ., abstract in Eng.)

3. Kovaleva, T.M., Zotkin, A.O., Sukhanova, E.A. (Eds) (2019). Stanovlenie t'yutorskoy modeli sovremennogo universiteta $v$ Rossii [Formation of the Tutor Model of the Modern University in Russia]. Tomsk: Tomsk State Univ. Publ. House, 256 p. (In Russ.)

4. Krivtsova, I.O. (2011). Socio-Cultural Adaptation of Foreign Students to the Educational Environment of the Russian University (on the Example of the Voronezh State Medical Academy named after N.N. Burdenko). Fundamental' nye issledovaniya = Fundamental Research. Vol. 8, no. 2, pp. 284-288. (In Russ., abstract in Eng.)

5. Belyaeva, T.K., Nikishina, O.A. (2015). Tutoring as a Resource for Improving the Quality of Education of Foreign Students at the University. Sovremennye problemy nauki i obrazovaniya = Modern Problems of Science and Education. No. 6. Available at: http://science-education.ru/ $\mathrm{ru} /$ article/view?id=22754 (In Russ.)

6. Gladush, A.D., Trofimova, G.N., Filippov, V.M. (2008). Social'no-kul'turnay aadaptatsiya inostrannykh grazhdan $k$ usloviyam obucheniya $i$ prozhivaniya $v$ Rossii [Social and Cultural Adaptation of Foreign Citizens to the Conditions of Study and Residence in Russia]. Moscow: RUDN Publ., 146 p. (In Russ.)

7. Samokhvalova, A.G., Dmitruk, L.A. (2019). Communication Difficulties of Chinese and Russian Students in Intercultural Communication. Yaroslavskij pedagogicheskii vestnik = Yaroslavl Pedagogical Bulletin. Vol. 4, no. 109, pp. 86-94. DOI: https://doi.org/10.24411/1813145X-2019-10456 (In Russ., abstract in Eng.)

8. Grebennikova, I.A. (2011). Adaptation of Foreign Students: Mechanisms and Factors. Gumanitarnye issledovaniya $v$ Vostochnoi Sibiri $i$ na Dal'nem Vostoke $=$ Humanities Research in the Russian Far East. No. 3, pp. 98-100. (In Russ., abstract in Eng.)

9. Kovaleva, T.M. (2014). Implementation of the Principle of Openness in the Construction and Application of Educational Technologies. Otechestvennaya $i$ Zarubezhnaya Pedagogika= National and Foreign Pedagogy. No. 4, pp. 63-71. (In Russ., abstract in Eng.)

10. Ivanova, G.P., Logvinova, O.K., Shirkova, N.N. (2018). Pedagogical Support of Socio-Cultural Adaptation of Foreign Students: Experience of Realization. Vysshee obrazovanie $v$ Rossii $=$ Higher Education in Russia. Vol. 27, no. 3, pp. 60-69. (In Russ., abstract in Eng.)

11. Gladkova, A.A. (2017). Psychological and Socio-Cultural Adaptation of International Journalism Students in Russia: The Role of Communication Skills in the Adaptation Process. Psychology in Russia: State of the Art. Vol. 10, no. 4, pp. 45-59. DOI: http://dx.doi.org/10.11621/ pir.2017.0405.

12. Kazantseva, A.A. (2012). Tutor Support of the Process of Adaptation of Foreign Students in the University. Vysshee obrazovanie v Rossii = Higher Education in Russia. No. 10, pp. 157-161. (In Russ., abstract in Eng.)

13. Kirilova, Yu.S. (2015). [Cultural and Mass Activity as One of the Important Ways of Adaptation of Foreign Students in Tomsk Polytechnic University]. Mezhdunarodnyi zburnal prikladnykb $i$ fundamental' nykb issledovanii [International Journal of Applied and Fundamental Research]. No. 5-4, pp. 670-672. (In Russ.) 
14. Belitskaya, E.V. (2012). The Current State of the Tutor System of Education in the Universities of England. Alma mater (Vestnik Vysshey Shkoly) = Alma Mater (Higher School Herald). No. 4, pp. 71-75. (In Russ., abstract in Eng.)

15. Proskurovskaya, I.D. (2009). The Experience of Reconstruction of the Historical Foundations of Tutoring (on the Material of the History of English Universities). Vestnik Tomskogo gosudarstvennogo universiteta. Filosofiya. Sotsiologiya. Politologiya $=$ Tomsk State University Journal of Pbilosopby, Sociology and Political Science. Vol. 2, no. 6, pp. 71-81. (In Russ., abstract in Eng.)

16. Gordon, E., Morgan, R., O’Malley, C., Ponticell, J. (2006). The Tutoring Revolution: Applying Research for Best Practices, Policy, and Student Achievement. New York: R\&L Education, 162 p. (Russian translation: Eds: S.F. Sirotkin, M.L. Melnikova, Izhevsk: ERGO, 2010, 332 p.)

17. Kovaleva, T.M., Cheredilina, M.Yu. (2015). T'yutorstvo kak resurs dlya sistemy razvivayushchego obucheniya D.B. El'konina-V.V. Davydova. [Tutoring as a Resource for the System of Developing Education by D.B. Elkonin - V.V. Davydov]. Moscow: Avtorskiy klub Publ., 56 p. (In Russ.)

18. Volchenkova, K.N. (2013). Tutor Support as the Basis of Subject-Subject Relations between Tutor and Student. Vestnik Yuzhno-Ural'skogo gosudarstvennogo universiteta. Obrazovanie. Pedagogicheskie nauki = Bulletin of the South Ural State University. Series "Education. Pedagogy”. Vol. 5, no. 3, pp. 71-76. (In Russ., abstract in Eng.)

The paper was submitted 12.10.19

Received after reworking 19.11 .19

Accepted for publication 30.11 .19

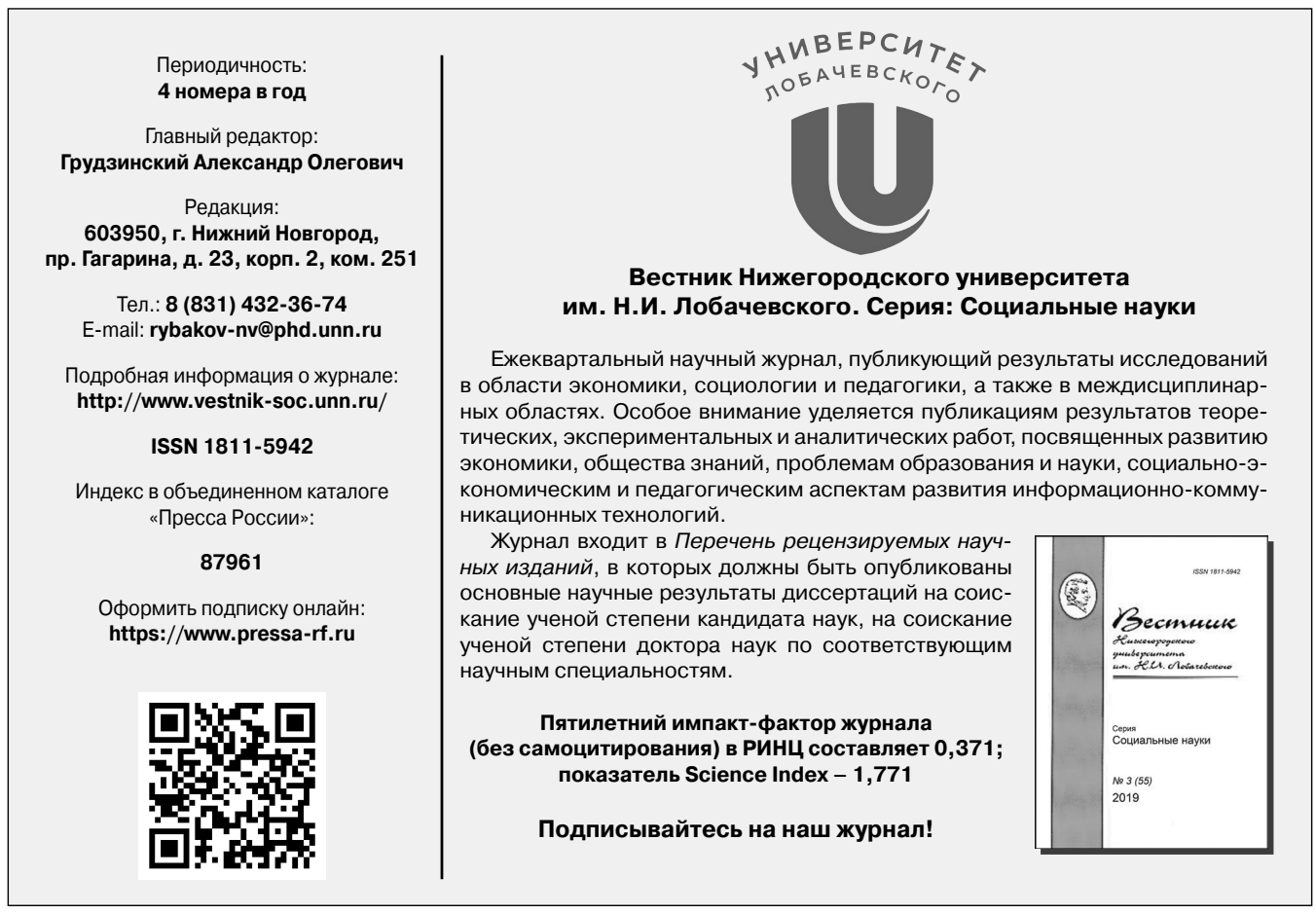

